\title{
Fusion of the Medial Clavicular Epiphysis in the South African and Kenyan Populations
}

\author{
Fusión de la Epífisis Clavicular Medial en las Poblaciones de Sudáfrica y Kenia
}

\author{
D. O. Marera \& K. S. Satyapal
}

MARERA, D. O. \& SATYAPAL, K. S. Fusion of the medial clavicular epiphysis in the South African and Kenyan populations. Int. J. Morphol., 36(3):1101-1107, 2018.

SUMMARY: Age estimation from clavicular ossification has been studied by many researchers based on the pattern and degree of the epiphyseal union through the use of dry bone specimens, radiographs, CT and MRI. These studies found clavicular ossification as a useful age indicator up to the third decade of life. The study aimed to document any population specific influence on age estimation using fusion processes of the clavicular epiphysis between the South African and Kenyan population groups. To achieve this objective a study of one thousand six hundred and five $(n=1605)$ digital radiographs of South African and Kenyan population groups, aged between 14-30 years, were evaluated. The ossification process of the medial clavicular epiphysis was scored against Schmeling's staging system. Growth variations between the two cohorts were carried out using student t-test analysis to assess for any significant differences between the means and standard deviations of the cohorts. A log linear regression test was also applied to test bilateral asymmetry in the ossification status for the medial epiphysis. The results of the paired linear model indicated a wide gap between chronological age (CA) and estimated age (EA) in patients under 20 years. The regression tests observed no significant difference between the EA of the South African and Kenyan populations. The current study yielded no significant differences in the ossification process of the medial clavicle amongst the Black South African and Kenyan populations when using Schmeling's staging system.

KEY WORDS: Clavicle; Sex; Laterality; Age estimation; ossification

\section{INTRODUCTION}

Age estimation has become an important area in forensic medicine due to the current increase in cross-border migration, globalization and the upsurge of conflicts in different regions of the world (Schmeling et al., 2004). Age estimation process is of essence in both forensic, medical and legal practice such as providing a correct judgment to adults or minors in legal proceedings. In Africa, there are no set standards of estimating a person's age (Schmeling et al.). This has led to inconsistencies in the age estimation process as different institutions or countries employ different methods for age estimation (Moindi et al., 2016). As a result, incorrect age estimation may lead to adverse consequences where a person is treated as an adult or vice versa (Moindi et al.).

Currently, variations in the time frame of medial epiphyseal union have been reported within different sexes, population groups, socio-economic strata and unicentral origins. Such variations have made bone age estimation a controversial subject in the field of forensic medicine, hence the call for population specific standards to address such issues. It is also disputable whether the age ranges for the phases of maturation developed by one technique (for example, dry bone studies) may be adapted to another method like radiological images (Kreitner et al., 1998; Schmeling et al.).

In this regard, there is a need for population specific standards for developing countries such as South Africa and Kenya, where birth records are not often well maintained, with secular trends continuously changing according to the advent of medical and social modernization (Moindi et al.).

Therefore, a harmonized radiological reference study is needed to aid forensic age estimation in the living individuals and instil confidence when being applied in legal proceedings.

The influence Population groups (Ethnicity). The influence of ethnicity on the rate of skeletal maturation has 
been widely controversial among authors and experts alike but the need to understand the relationship between the two is crucial in the field of forensic medicine (Udoaka \& Nwokediuko, 2013; Wittschieber et al., 2014). This is important when one intends to estimate the age of individuals using reference standards originating from a different population group (Garn et al., 1966; Bhabha \& Finch, 2006). South Africa has a large number of immigrants from different ethnic groups and from different countries, while Kenya has the largest refugee camp in the world (Aronson, 2011). Therefore, there is a need to take ethnicity into account when clavicular age assessment is carried out.

Some researchers have reported the difference in the ossification process of a population of multiple ethnic groups living in the same place (Greulich \& Pyle, 1950; Loder et al., 1993; Nyati et al., 2006). From their work, they noted a significant variation in the fusion and maturation process of epiphyseal plates, even when different methodologies were applied in their studies.

To narrow down on the African population, Dembetembe (2010) studied age estimation using fusion of epiphyseal plates of the wrist joint in subjects within the age range of 14 to 22 years. He noted a delay in the maturation process of the African samples when compared to the Greulich and Pyle standard. Dembetembe concluded that the varying results were likely attributed to environmental and socioeconomic variations from the reference populations. This calls for more studies to develop population specific reference standards in each population group.

To confirm the reliability of age estimation atlases, authors noted that some atlases improved accuracy rates in a population whilst other atlases did not (Schmeling et al.). No individual atlas could be applied accurately to all population groups, whilst other atlases were completely unreliable among specific population groups (Malina \& Little, 1981). Schmeling et al. reviewed over eighty (80) of such studies and assessed the correlation between ethnic origin and epiphyseal fusion using x-rays. Schmeling et al. observed that the chronological process of fusion was similar and the pattern of growth was constant between different ethnic groups. Table I below presents variations in the ossification processes as observed from different countries and by different authors. Against this background, this study aimed to document any population specific influence on age estimation using the fusion process of the clavicular epiphysis amongst the South African and Kenyan populations.

\section{MATERIAL AND METHOD}

One thousand six hundred and five radiographs $(n=1605)$ from the Black South African and Kenyan populations aged between 14 and 30 years met the inclusion criteria. Permission to collect data was granted by the Radiology Department at King Edward VIII Hospital, within the eThekwini Municipality, South Africa and West Kenya Diagnostics and Imaging Center, Kisumu, Kenya. Ethical approval was obtained from the University of Kwa-Zulu Natal (BE 267/14). The sex and date at which the radiographs were taken were recorded for analysis. Each respondent's actual age (CA) was recorded after the staging process and the EA was established to avoid bias.

The stages of maturity and union of the medial clavicular epiphysis were then observed and recorded chronologically according to the scoring system of Schmeling et al. for the medial clavicle as follows (Fig. 1):

Stage 1: No fusion of ossification taking place (Stage 1 is observed when the medial end of the clavicle has a thin margin that is curved inwards).

Stage 2: Visible ossification center, but the epiphyseal plates are not fused

Table I. Ossification of the medial clavicular epiphysis using radiological techniques (X-ray or CT).

\begin{tabular}{|c|c|c|c|c|c|c|c|}
\hline Author & Study area & Sex & Stage 1 & Stage 2 & Stage 3 & Stage 4 & Stage 5 \\
\hline \multirow{2}{*}{ Kellinghaus et al. (2010) } & \multirow[t]{2}{*}{ Germany } & Male & $10-16$ & $14-20$ & $17-26$ & $22-35$ & $26-35$ \\
\hline & & Female & $10-16$ & $13-19$ & $16-26$ & $21-35$ & $26-35$ \\
\hline \multirow{2}{*}{ Cameriere et al. (2012) } & \multirow[t]{2}{*}{ Italy } & Male & $13-21$ & $15-23$ & $17-24$ & $19-27$ & $21-26$ \\
\hline & & Female & $14-19$ & $15-20$ & $17-24$ & $19-26$ & $21-26$ \\
\hline \multirow{2}{*}{ Wittschieber et al. (2014) } & \multirow[t]{2}{*}{ Germany } & Male & $11-14$ & $15-20$ & $16-36$ & $21-40$ & $26-40$ \\
\hline & & Female & 12.-15 & $14-18$ & $15-26$ & $21-37$ & $26-39$ \\
\hline \multirow{2}{*}{ Kaur (2013) } & \multirow[t]{2}{*}{ India } & Male & $12-17$ & $15-18$ & $16-25$ & $21-29$ & $26-30$ \\
\hline & & Female & $12-17$ & $14-18$ & $15-25$ & $20-30$ & $25-30$ \\
\hline \multirow{2}{*}{ Current study } & \multirow[t]{2}{*}{ Kenya and South Africa } & Male & $14-19$ & $17-23$ & $19-26$ & $24-27$ & $26-30$ \\
\hline & & Female & $14-20$ & $14-23$ & $16-26$ & $23-27$ & $26-30$ \\
\hline
\end{tabular}

Key: ND- No Data recorded. 


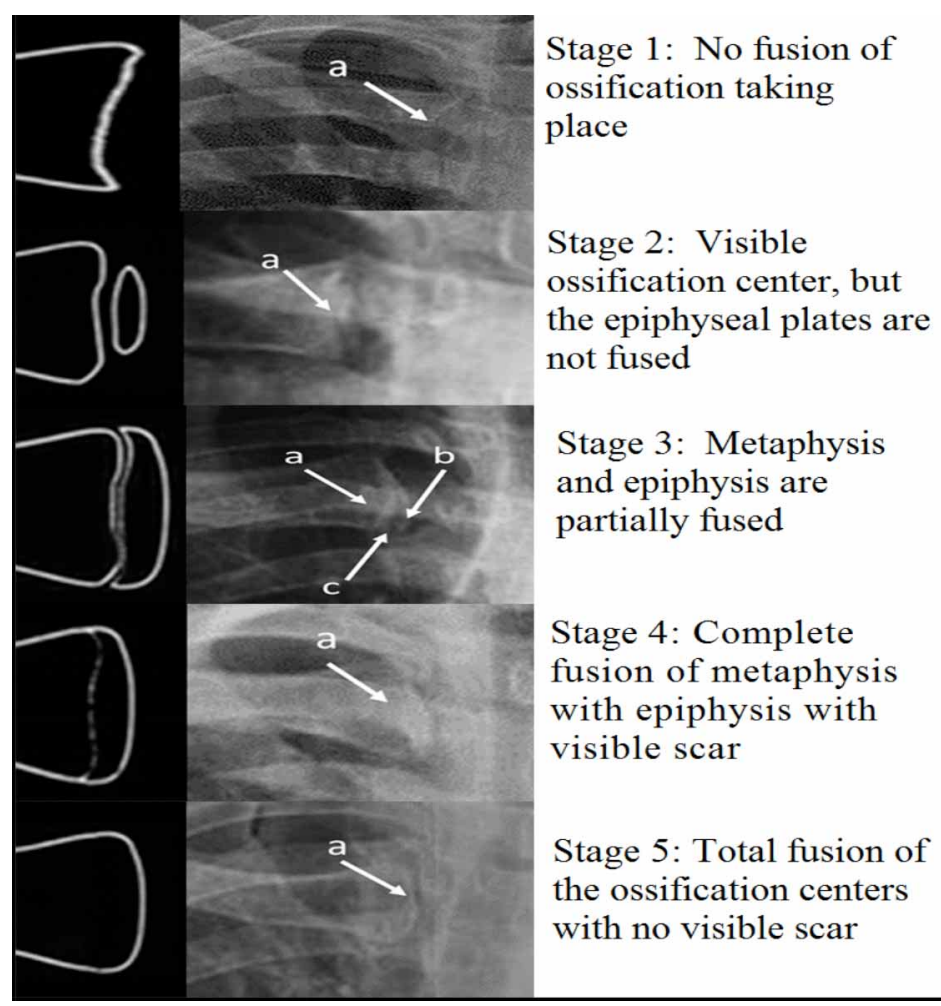

Fig. 1. Stages of fusion of medial clavicular epiphysis according to the scoring system of Schmeling et al. (2004) Key: a = Epiphyses, b = Bone tubercle closing the gap between epiphyses and metaphysis, $\mathrm{c}=$ Metaphysis.

Stage 3: Metaphysis and epiphysis are partially fused.

Stage 4: Complete fusion and union of metaphysis with epiphysis, but with a visible scar - This stage describes the complete union of the epiphysis and metaphysis of the medial clavicle.

Stage 5: Total fusion of the ossification centers without any visible union scar.

The study was subjected to analysis using Statistical Package for Social Sciences (Release 21.0.1, SPSS Inc. 1989-2001) for Windows 10 . To evaluate the growth variations between the two cohorts (South Africa and Kenya), a t-test was carried out to assess

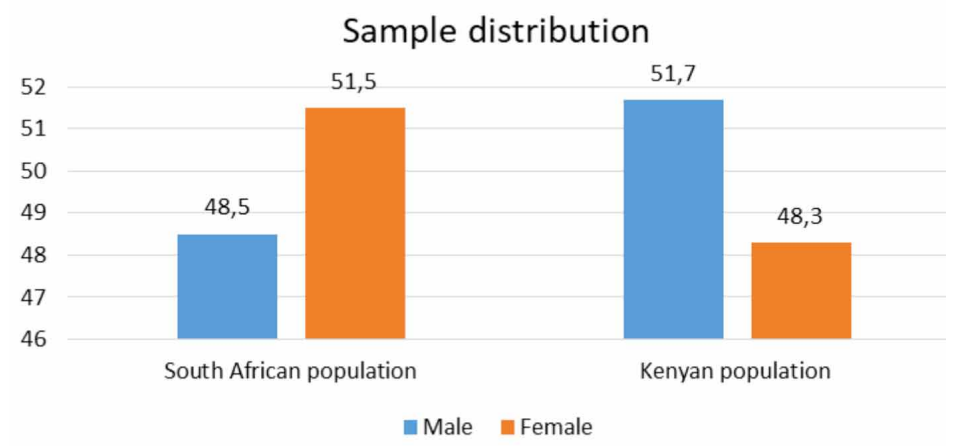

Fig. 2. Frequency distribution of the South African and Kenyan population groups. for any significant differences between the means and standard deviations between the cohorts. The cohorts were categorised as independent groups for consistency of the results (unrelated t-test). The difference in the estimated age was calculated to produce $\mathrm{p}$ values (a test for significance).

The difference between CA and EA for each population group (South Africa and Kenya) was presented in a Bland-Altman plot at a confidence interval of $95 \%$. The correlation of age with the ossification status of bilateral medial clavicular epiphyses was determined for both sexes.

The age intervals corresponding to different ossification stages were also compared between the sexes within the two population groups. A log linear regression test was used to test bilateral asymmetry in the ossification status for medial epiphyses. Significance was assessed at $p<0.05$ (exact, two-sided), whilst cross-tabulation was done between the EA and the 5 stages of ossification to determine the reliability and margin of error of this method of age estimation.

\section{RESULTS}

Age distribution. A total of one thousand one hundred and five $(\mathrm{n}=1605)$ chest $\mathrm{X}$-rays of patients aged between 14 to 30 years met the inclusion criteria and were assessed for the fusion process. Of the selected X-rays, $48 \%(771 / 1605)$ were Black South Africans with a mean age of $22.8 \pm$ 4.8 years and $52 \%(834 / 1605)$ were Kenyans with a mean age of $22.6 \pm 4.7$ years. The sex distribution of the selected sample was $50.2 \%(805 / 1605)$ males and $49.8 \%(800 / 1605)$ females. The mean age of the sample was $22.70 \pm 0.12$ years, with a median age of 23 years (Fig. 2).

Regression test for significance between the cohorts. The bivariate linear regression permits estimation of the relationship between the estimated age (EA) of the South African and EA of the Kenyan population groups. It presents a continuous dependent response to the variable (EA). Accordingly, the results observed no significant difference between EA for the South African and Kenyan populations $(\mathrm{p}=1.150)$ (Table II). 
Table II. Paired sample t-test testing for significant differences in estimated age of the South African and Kenyan population groups.

\begin{tabular}{lccccccc}
\hline & \multicolumn{8}{c}{ Paired Samples T-Test } \\
\hline \multicolumn{1}{c}{ Test } & B & SE & Beta & Sig. & Cohen's d & 95\%Confidence Interval \\
Null & -11.41 & 0.27 & - & 0.813 & 1.751 & -11.975 & -10.851 \\
Correlate & 0.939 & 0.01 & 0.9570 & 1.150 & 1.751 & 0.914 & 0.964 \\
\hline
\end{tabular}

Table III. Mean age differences between males and females in the South African and Kenyan population groups.

\begin{tabular}{cccccccc}
\hline \multicolumn{7}{c}{ Mean ages of the medial clavicle } \\
\hline Country & Sex & Stage 1 & Stage 2 & Stage 3 & Stage 4 & Stage 5 & $P$ value \\
\hline Male & South Africa & 15.14 & 19.57 & 22.74 & 25.62 & 28.79 & 0.213 \\
& Kenya & 16.41 & 20.5 & 23.44 & 25.86 & 28.64 & \\
Female & South Africa & 15.34 & 17.9 & 22.43 & 25.81 & 28.71 & 1.15 \\
& Kenya & 15.4 & 19.5 & 23.39 & 25.87 & 28.7 & \\
\hline
\end{tabular}

Sex dimorphism in the medial epiphysis between the cohorts. In the medial epiphysis, there were no statistically significant differences in EA between the South African and Kenyan males $(p=0.213)$ and South African and Kenyan females $(p=1.15)$ (Table III). However, significant differences in growth rates between males and females was observed in both cohorts.

Difference in the incidence of asymmetry between the cohorts. Asymmetry in the maturation process was recorded at $1.08 \%$ (4/374) and $2.1 \%$ (9/431) in the South African and Kenyan male population groups $(\mathrm{p}=1.971)$. In the female population, the incidence of asymmetry was observed at $3.5 \%(14 / 403)$ and $4.12 \%(16 / 397)$ in the South African and Kenyan population groups, respectively $(\mathrm{p}=1.013)$. No statistically significant difference in the maturation process was observed between the two cohorts (Fig. 3).

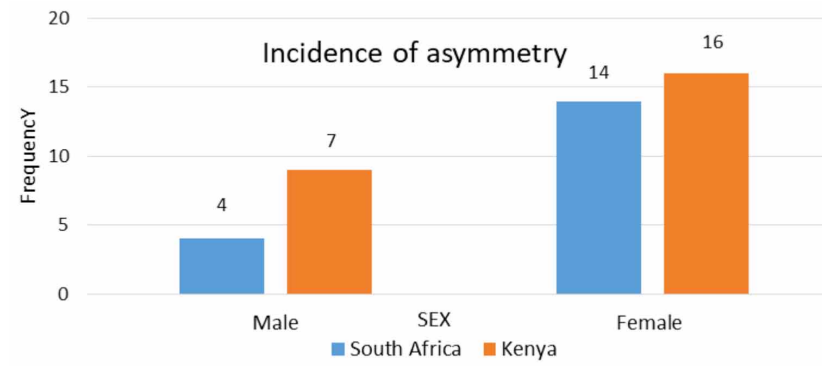

Fig. 3. The sex difference in the incidence of asymmetry in the South African and Kenyan population groups.
The standard variation trends in age estimation between the South African and Kenyan population groups. The results of the paired linear model indicated a wide gap between the CA and EA in patients under 20 years (standard error of $1.1 \pm 1.01$ years). This was followed by a gradual narrowing in the gap between the CA and EA at a standard error of $0.9 \pm 0.4$ years, as the patients approached the third decade of life. This indicates that the level of accuracy in age estimation increases as one approaches the third decade of life as presented by the narrowing gap between the EA and CA (represented by the black line) (Fig. 4).

The standard predicted mean difference between chronological age and estimated age in the South African and Kenyan population groups. Using the standard residual statistics, the predicted standard error of mean (SEM) was \pm 1.46 years in the South African population. The SEM was \pm 1.45 years and \pm 1.47 years in male and female South Africans, respectively. The maximum age under prediction of -1.78 years and the maximum age over prediction of 1.66 years was observed in the males. In the female patients, a maximum age under prediction of -1.81 years and maximum over prediction of 1.47 years was observed.

With respect to the Kenyan patients, the predicted SEM was 1.44 years. The predicted SEM was \pm 1.41 years in males with a maximum age under prediction of -1.79 years and maximum age over prediction of 1.56 years. In females, the predicted SEM was \pm 1.46 years with a maximum under prediction of -2.1 years and an over prediction of 2.28 was reported (Fig. 5). 


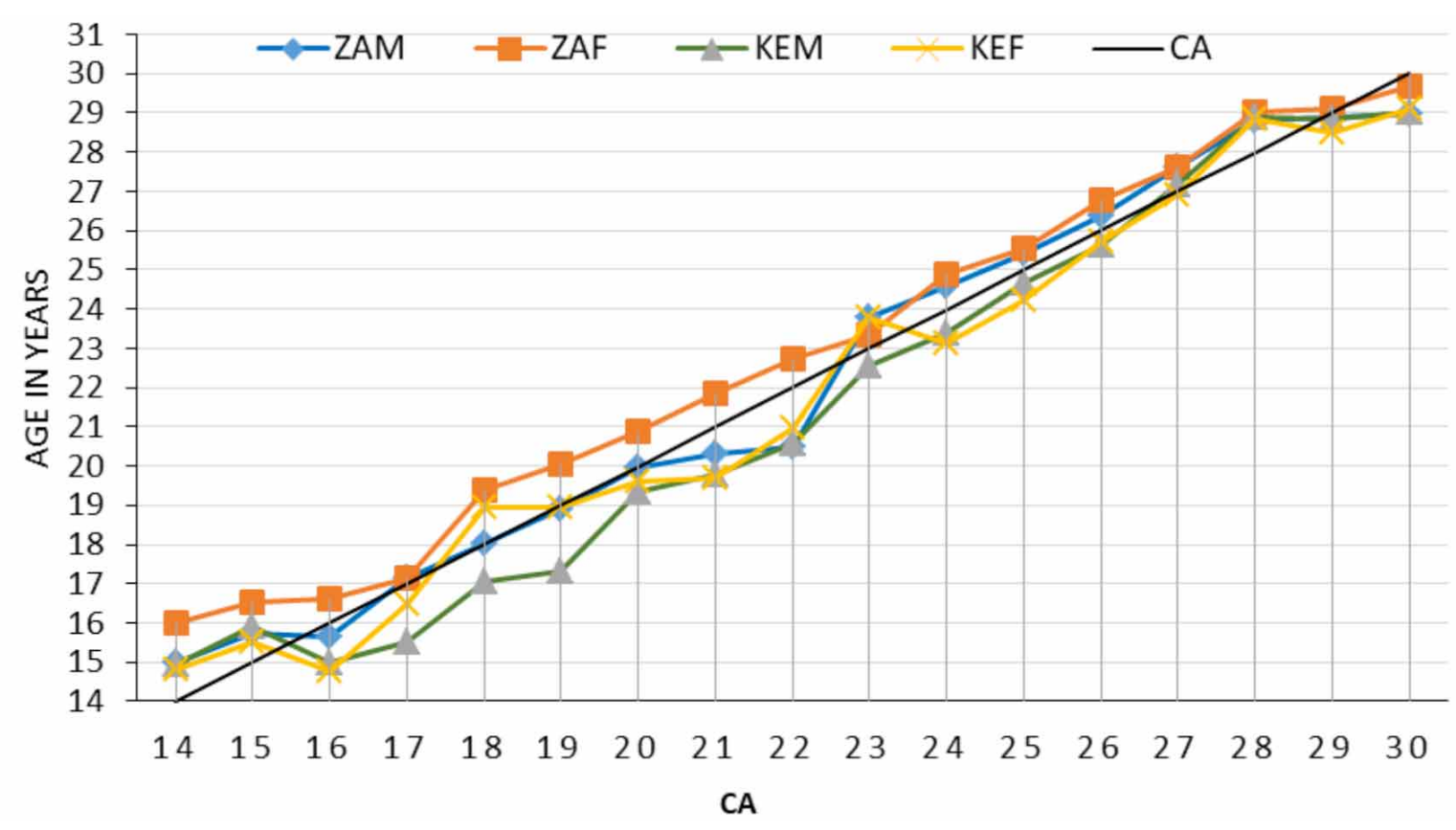

Fig. 4. Sex comparison between CA and EA within the South African and Kenyan population groups (The black line denotes the trend in estimated age). Key: ZAM = South African male population, ZAF = South African female population, $\mathrm{KEM}=$ Kenyan male population, $\mathrm{KEF}=$ Kenyan female population $\mathrm{CA}=$ Chronological Age

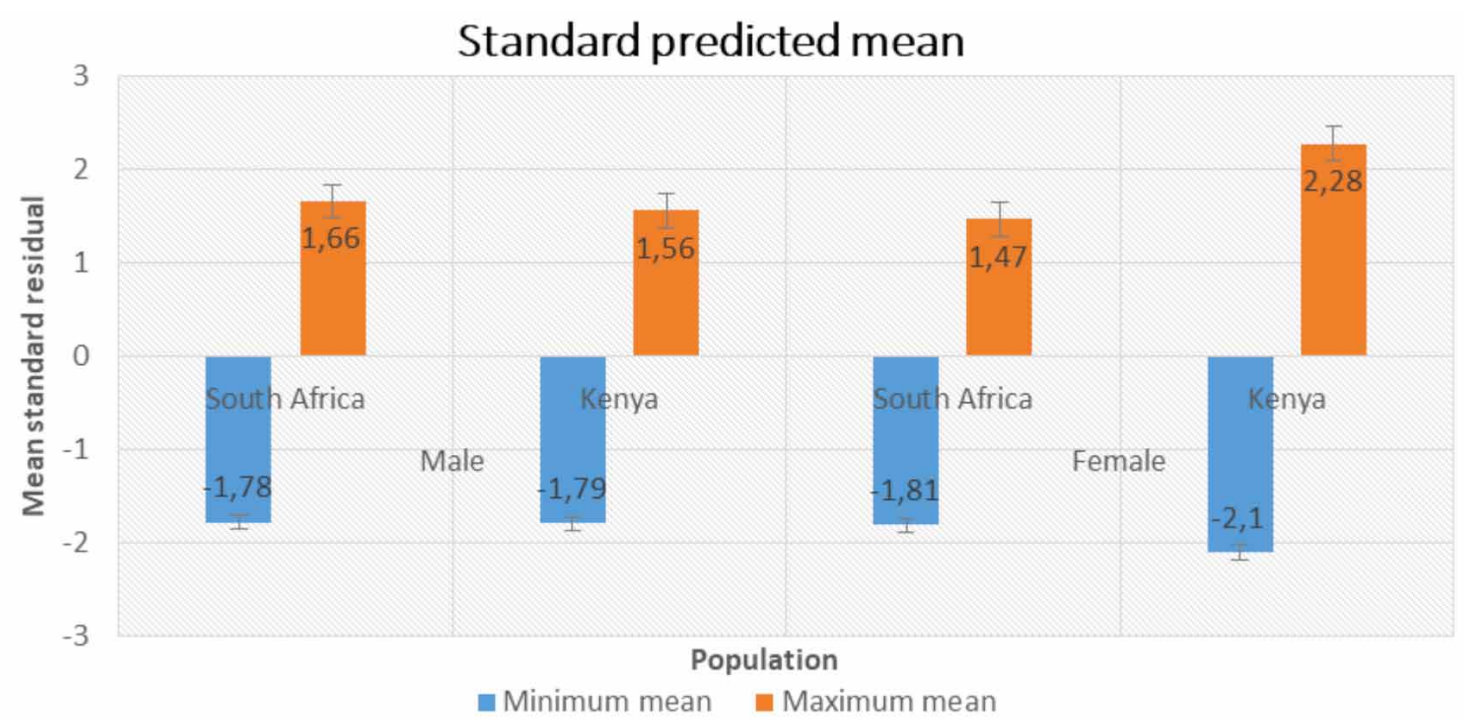

Fig. 5. The predicted mean residual between chronological age and predicted age (EA) in the South African and Kenyan population groups.

\section{DISCUSSION}

Age estimation using medial clavicular epiphysis was assessed with considerable reliability in both cohorts. The age assessment was more precise in males than in the female cohorts for both countries. The current findings provided a significant estimate and improvement to the scarce reference in the African setting. In addition, it is worth noting that the 
calculated age intervals in the present study were considerably more precise than those obtained using other bones such as the femur, skull or pelvis. The current study, therefore, reinforces the proposition that the Greulich and Pyle Atlases are not applicable in the African setting (Bassed et al., 2011).

Variations in the time frame of ossification of the medial epiphysis. When comparing the results of different studies of various population groups, varying results and references were observed in the maturation process of the medial epiphysis (Schmeling et al.; Bassed et al.). In the current study, two population groups of the same ancestry, but different geographic settings and ethnicity were subjected to similar study parameters of age assessment. This was designed to observe any existing population specific variations while comparing the results with the previously established references.

The current study attempted to answer one relevant question as to whether the reference to one population may be used to assess subjects of different demographic origin and ethnicity, but of similar ancestry. No significant differences in growth rates between the two cohorts were observed in the right and left clavicle. In addition, the average SEM was 1.44 and 1.43 in the South African and Kenyan cohorts, respectively. Therefore, the reference values established in the present study may be applicable to members of the same African population. Table I illustrates the variations in the ossification of medial clavicular epiphysis from different countries.

The influence of Socio-economic status in age estimation. Through Probit regression analysis, no statistically significant difference in the ossification process of the South African and the Kenyan population groups was observed. In addition, there was also no significant socioeconomic influence on age estimation in the current population groups (Table III). This concured with the conclusions of Lakha (2015), who observed that socioeconomic status and ethnicity did not affect the epiphyseal fusion process of the South African children. In addition, Dembetembe also noted that socio-economic status had no significant influence on age estimation in the South African population. The two countries share a lot in common in terms of cultural, medical, education, ancestral heritage and environmental setting. These factors make the two cohorts to present as a homogenous community within the African setting.

One important question of practical relevance in the present study is whether the results of previous studies developed from the Northern Hemispheric population could be used as a reference to subjects of different population groups, socio-economic status and different sexes. In this regard, the results of the present study demonstrated no significant difference in age estimation between the South African and Kenyan population groups. In addition, the average SEM was 1.44 and 1.43 in the South African and Kenyan cohorts, respectively. Accordingly, reference standards developed for the Black South African population may be applied in the Kenyan population group.

The results of this study confirmed the significant variations of sex dimorphism in the time frame of epiphyseal union as presented in the previous literature. Males mature 1 to 2 years later than females. Thus, males and females were presented differently in the proposed reference standards of the current study. On the contrary, socioeconomic status of the population did not influence the maturation process of the clavicle of the cohort.

In both cohorts, bilateral asymmetry in the fusion of the right and left clavicular epiphysis was confirmed. However, the incidence was not significant enough to influence the age estimation process as reported in previous literature. The occurrence of asymmetry was higher in females than in the male patients. These maturation gaps were mostly observed at stages 1 and 2 . Nonetheless, it was not possible to determine which side matured faster than the other as earlier maturation was observed on both the right and left sides. Where a person presents with variations in maturation between the right and left epiphyses, the least developed side is considered for age estimation.

\section{CONCLUSION}

The current study evidenced no significant differences in the ossification process of the medial clavicle amongst the Black South African and Kenyan populations when using Schmeling et al. staging system and thus a similar reference value may be used for the two cohorts for age estimation purposes.

Evidence from the current study demonstrated that a digital X-ray study of the clavicular epiphysis provides a reliable age estimation technique. Therefore, given that conventional X-rays are readily available in health-care systems throughout Africa, it may be practical and feasible to implement the present technique. However, to improve precision, age estimation using digital X-rays should strictly apply the reference standards developed by the same conventional X-ray technique. 
MARERA, D. O. \& SATYAPAL, K. S. Fusión de la epífisis clavicular medial en las poblaciones de Sudáfrica y Kenia. Int. J. Morphol., 36(3):1101-1107, 2018.

RESUMEN: La estimación de la edad a partir de la osificación clavicular ha sido estudiada por muchos investigadores según el patrón y el grado de unión epifisaria mediante el uso de muestras de hueso seco, radiografías, tomografía computarizada y resonancia magnética. Estos estudios encontraron la osificación clavicular como un indicador de edad útil hasta la tercera década de la vida. El estudio tuvo como objetivo documentar cualquier influencia específica de la población en la estimación de la edad utilizando los procesos de fusión de la epífisis clavicular entre los grupos de población de Sudáfrica y Kenia. Para lograr este objetivo, se evaluó un estudio de mil seiscientas cinco $(n=1605)$ radiografías digitales de grupos de la población de Sudáfrica y Kenia, con edades comprendidas entre 14 y 30 años. El proceso de osificación de la epífisis clavicular medial se puntuó frente al sistema de estadificación de Schmeling. Las variaciones de crecimiento entre las dos cohortes se llevaron a cabo utilizando la prueba t de Student para evaluar las diferencias significativas entre las medias y las desviaciones estándar de las cohortes. También se aplicó una prueba de regresión lineal para evaluar la asimetría bilateral en el estado de osificación de la epífisis medial. Los resultados del modelo lineal indicaron una gran brecha entre la edad cronológica (CA) y la edad estimada (EA) en pacientes menores de 20 años. En las pruebas de regresión no se observaron diferencias significativas entre la EA de las poblaciones de Sudáfrica y Kenia. El presente estudio no presentó diferencias significativas en el proceso de osificación epífisis medial de la clavícula entre las poblaciones negras de Sudáfrica y Kenia cuando se usó el sistema de estadificación de Schmeling et al.

PALABRAS CLAVE: Clavícula; Sexo; Lateralidad; Estimación de edad; Osificación.

\section{REFERENCES}

Bassed, R. B.; Briggs, C. \& Drummer, O. H. Age estimation using CT imaging of the third molar tooth, the medial clavicular epiphysis, and the spheno-occipital synchondrosis: a multifactorial approach. Forensic Sci. Int., 212(1-3):273.e1-5, 2011.

Bhabha, J. \& Finch, N. Seeking Asylum Alone: Unaccompanied and Separated Children and Refugee Protection in the UK. Brighton, Child Migration Research Network, 2008. Available from: http:// www.childmigration.net/Bhabha_06

Cameriere, R.; De Luca, S.; De Angelis, D.; Merelli, V.; Giuliodori. A.; Cingolani, M.; Cattaneo, C. \& Ferrante, L. Reliability of Schmeling's stages of ossification of medial clavicular epiphyses and its validity to assess 18 years of age in living subjects. Int. J. Legal Med., 126(6):92332, 2012.

Dembetembe, K. A. Age Estimation Using Epiphyseal Closure at the Wrist Joint. An Investigation of Individuals of African Origin, Age 14 to 22 Years. M. Sc. Thesis. Cape Town, University of Cape Town, 2010.

Garn, S. M.; Rohmann, C. G. \& Blumenthal, T. Ossification sequence polymorphism and sexual dimorphism in skeletal development. Am. J. Phys. Anthropol., 24(1):101-15, 1966.

Greulich, W. W. \& Pyle, S. I. Radiographic Atlas of Skeletal Development of the Hand and Wrist. Stanford, Stanford University Press, 1950.

Kaur, G. Radiological study of clavicle for age estimation. Ph.D. Thesis in Forensic Sciences. Patiala, Punjabi University, 2013.

Kellinghaus, M.; Schulz, R.; Vieth, V.; Schmidt, S.; Pfeiffer, H. \& Schmeling, A. Enhanced possibilities to make statements on the ossification status of the medial clavicular epiphysis using an amplified staging scheme in evaluating thin-slice CT scans. Int. J. Legal Med., 124(4):321-5, 2010.

Kreitner, K. F.; Schweden, F. J.; Riepert, T.; Nafe, B. \& Thelen, M. Bone age determination based on the study of the medial extremity of the clavicle. Eur. Radiol., 8(7):1116-22, 1998.

Lakha, K. N. Standards for epiphyseal union in South African children between the ages of 6 to 24 years using low dose X-ray (lodox). Ph.D. Thesis. Cape Town, University of Cape Town, 2015.

Loder, R. T.; Estle, D. T.; Morrison, K.; Eggleston, D.; Fish, D. N.; Greenfield, M. L. \& Guire, K. E. Applicability of the Greulich and Pyle skeletal age standards to black and white children of today. Am. J. Dis. Child., 147(12):1329-33, 1993.

Malina, R. M. \& Little, B. B. Comparison of TW1 and TW2 skeletal age differences in American black and white and in Mexican children 6-13 years of age. Ann. Hum. Biol., 8(6):543-8, 1981.

Moindi, R. O.; Ngari, M. M.; Nyambati, V. C. S. \& Mbakaya, C. Why mothers still deliver at home: understanding factors associated with home deliveries and cultural practices in rural coastal Kenya, a crosssection study. B. M. C. Public Health, 16:114, 2016.

Nyati, L. H.; Norris, S. A.; Cameron, N. \& Pettifor, J. M. Effect of ethnicity and sex on the growth of the axial and appendicular skeleton of children living in a developing country. Am. J. Phys. Anthropol., 130(1):13541, 2006.

Schmeling, A.; Schulz, R.; Reisinger, W.; Mühler, M.; Wernecke, K. D. \& Geserick, G. Studies on the time frame for ossification of the medial clavicular epiphyseal cartilage in conventional radiography. Int. J. Legal Med., 118(1):5-8, 2004.

Udoaka, A. I. \& Nwokediuko, A. U. Radiologic evaluation of clavicular morphology in southern Nigerians. Int. J. Morphol., 31(1):94-9, 2013.

Wittschieber, D.; Schulz. R.; Vieth, V.; Küppers, M.; Bajanowski, T.; Ramsthaler, F.; Püschel, K.; Pfeiffer H.; Schmidt, S. \& Schmeling, A. The value of sub-stages and thin slices for the assessment of the medial clavicular epiphysis: a prospective multi-center CT study. Forensic Sci. Med. Pathol., 10(2):163-9, 2014.

Corresponding author:

Professor K. S. Satyapal

Department of Clinical Anatomy

School of Laboratory Medicine and Medical Sciences

College of Health Sciences

University of KwaZulu-Natal

Private Bag X54001

Durban

4000

SOUTH AFRICA

Email: satyapalk@ukzn.ac.za

Received: 06-12-2017

Accepted: 28-06-2018 